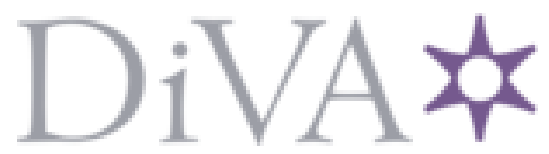

http://www.diva-portal.org

This is the published version of a paper published in Chemistry of Materials.

Citation for the original published paper (version of record):

Yao, Q., Bermejo Gómez, A., Su, J., Pascanu, V., Yun, Y. et al. (2015)

Series of Highly Stable Isoreticular Lanthanide Metal-Organic Frameworks with Expanding

Pore Size and Tunable Luminescent Properties.

Chemistry of Materials, 27(15): 5332-5339

https://doi.org/10.1021/acs.chemmater.5b01711

Access to the published version may require subscription.

N.B. When citing this work, cite the original published paper.

Reprinted with permission of Chemistry of Materials, 27(15): 5332-5339. Copyright 2015. American Chemical Society.

Permanent link to this version:

http://urn.kb.se/resolve?urn=urn:nbn:se:su:diva-120686 


\title{
Series of Highly Stable Isoreticular Lanthanide Metal-Organic Frameworks with Expanding Pore Size and Tunable Luminescent Properties
}

\author{
Qingxia Yao, ${ }^{\dagger, \ddagger, \|, \#}$ Antonio Bermejo Gómez, ${ }^{\dagger, \S, \perp, \#}$ Jie Su, ${ }^{\dagger, \ddagger, \#}$ Vlad Pascanu, ${ }^{\dagger, \S}$ Yifeng Yun, ${ }^{\dagger, \ddagger}$ \\ Haoquan Zheng, ${ }^{\dagger, \dagger}$ Hong Chen, ${ }^{\dagger, \uparrow}$ Leifeng Liu, ${ }^{\dagger, \ddagger}$ Hani Nasser Abdelhamid, ${ }^{\dagger, \ddagger}$ Belén Martín-Matute, ${ }^{*},, \S$ \\ and Xiaodong Zou*, ${ }^{*},+$
}

${ }^{\dagger}$ Berzelii Center EXSELENT on Porous Materials, Arrhenius Laboratory, Stockholm University, Stockholm, SE-106 91, Sweden

${ }^{\ddagger}$ Department of Materials and Environmental Chemistry, Stockholm University, Stockholm, SE-106 91, Sweden

${ }^{\S}$ Department of Organic Chemistry, Stockholm University, Stockholm, SE-106 91, Sweden

\section{Supporting Information}

ABSTRACT: A series of highly porous isoreticular lanthanidebased metal-organic frameworks (LnMOFs) denoted as SUMOF-7I to SUMOF-7IV (SU = Stockholm University; Ln $=\mathrm{La}, \mathrm{Ce}, \mathrm{Pr}, \mathrm{Nd}, \mathrm{Sm}, \mathrm{Eu}$, and Gd) have been synthesized using tritopic carboxylates as the organic linkers. The SUMOF-7 materials display one-dimensional pseudohexagonal channels with the pore diameter gradually enlarged from 8.4 to $23.9 \AA$, as a result of increasing sizes of the organic linkers. The structures have been solved by single crystal X-ray diffraction or rotation electron diffraction (RED) combined with powder X-ray diffraction (PXRD). The SUMOF-7 materials exhibit robust architectures with permanent porosity. More importantly, they exhibit exceptionally high thermal and chemical stability. We show that, by inclusion of organic dye molecules, the luminescence properties of the MOFs can be elaborated and modulated, leading to promising applications in sensing and optics.

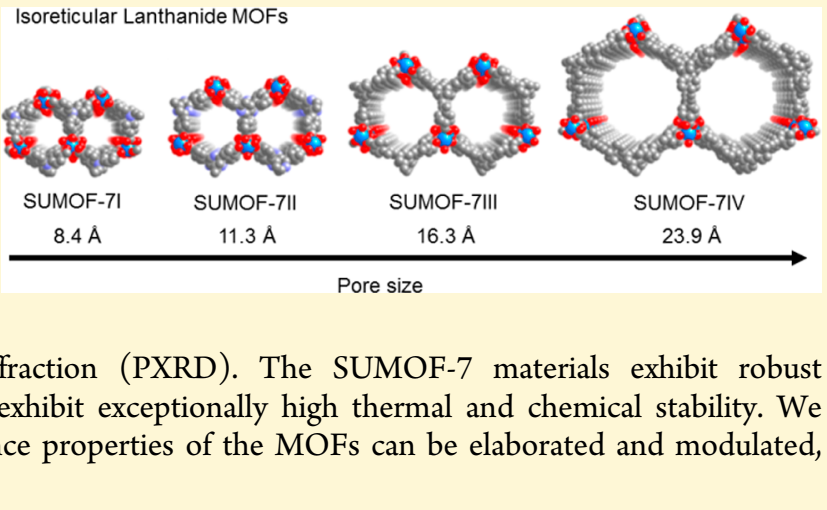

\section{INTRODUCTION}

Systematic design and control of pore size, shape, and functionality in porous crystalline framework materials, without changing the underlying topology, have attracted large attention. This isoreticular principle has been successfully demonstrated in metal-organic frameworks (MOFs) by choosing constituent building blocks with desired functionality. ${ }^{1-3}$ Consequently, the design and synthesis of isoreticular MOFs have been an attractive area of research during the recent years. $^{4-8}$ It represents a rational approach toward applications that require size or shape selectivity, such as sorption, separation, and heterogeneous catalysis. The most common approach to synthesize isoreticular MOFs with different pore sizes is to combine metal clusters and organic linkers of various sizes. This has been demonstrated by combining metal clusters with ditopic linkers such as in the IRMOF-n series with tetrameric Zn clusters, ${ }^{9}$ the MIL- $88^{10}$ and MIL-101 ${ }^{11,12}$ series with trimetric metal clusters, and the UiO66 series with hexameric $\mathrm{Zr}$ clusters. ${ }^{13}$ Isoreticular MOFs have also been synthesized by combining metal clusters with tritopic linkers, such as in the HKUST-1 series with dimeric metal paddle-wheel clusters ${ }^{14-17}$ and the MIL-100 series ${ }^{11,18}$ with trimeric metal clusters. Tetratopic porphyrines have also been used with hexameric $\mathrm{Zr}$ clusters to form a series of isoreticular porphyrinic MOFs. ${ }^{19,20}$ Another approach of designing MOFs with expanding pores is to use inorganic chain building units. The advantage of using inorganic chains is that a wide range of metals, from alkaline-earth metal, aluminum, and transition metals to rare-earth metals, can form inorganic chains. Interpenetration may be avoided so that pores can be extended. $^{21}$ Isoreticular MOFs built from inorganic chains and ditopic linkers have been synthesized, such as in the series of IRMOF-74 with $\mathrm{Mg}, \mathrm{Zn}$, or $\mathrm{Al}$ chains, ${ }^{22}$ and in the series of STA-12 and STA-16 with Co phosphonate spiral chains ${ }^{23}$ and in the MIL-140 series with $\mathrm{Zr}$ chains. ${ }^{24}$ Although MOFs built from inorganic chains and tritopic linkers have been reported, ${ }^{25,26}$ to the best of our knowledge, there is no report on isoreticular MOFs with expanding pore sizes based on tritopic linkers.

We have been interested in synthesizing isoreticular MOFs using tritopic linkers and prepared a novel SUMOF-5 built from dicopper paddle-wheel clusters and pyridine-2,4,6tribenzoate $(\mathrm{PTB})^{17}$ which is isoreticular to HKUST-1. ${ }^{14}$ However, similar to most isoreticular MOFs, SUMOF-5 was not thermally and chemically stable. In the search for more stable isoreticular MOFs using tritopic linkers, we identified

Received: May 7, 2015

Revised: July 8, 2015

Published: July 9, 2015 
lanthanide-based MOFs (LnMOFs) as our candidates. This is because LnMOFs show high stability and unique luminescent, $^{27-32}$ magnetic, ${ }^{33,34}$ catalytic, ${ }^{26,35}$ and chemical sensing properties. $^{36}$ Furthermore, the organic linkers may serve as antennae to sensitize lanthanide emissions. However, the number of LnMOFs that show permanent porosity is still limited, ${ }^{37-53}$ and those with large pores are even scarcer. $^{21,25,38,40,45,51}$ Furthermore, due to the lack of directionality of the $\mathrm{Ln}-\mathrm{O}$ bond, ${ }^{54}$ it is rather difficult to synthesize LnMOFs with predictable structures. Thus, it remains a significant challenge to synthesize isoreticular porous lanthanide-based MOFs with controllable and predictable pore sizes.

Here we present a new series of highly stable porous isoreticular LnMOFs with one-dimensional (1D) pseudohexagonal channels (denoted SUMOF-7I, -7II, -7III, and -7IV; SU = Stockholm University; Ln = La, Ce, Pr, Nd, Sm, Eu, and Gd) by combining Ln-carboxylate inorganic chains and tritopic organic linkers of variable sizes. SUMOF-7I, -7II, and -7III show extraordinary thermal stability and remarkable tolerance toward hot water, organic solvents (i.e., N,N-dimethylformamide DMF), and aqueous media with $\mathrm{pH}$ values ranging from 2 to 11 . These materials exhibit permanent porosity and interesting luminescence properties. As an example, we show that the emission of these materials can be tuned by doping with different ratios of lanthanide ions as well as by incorporating guest dye molecules in the pores.

\section{EXPERIMENTAL SECTION}

Details of the synthetic routes for the tritopic linkers $\mathrm{H}_{3} \mathbf{L} \mathbf{1}-\mathrm{H}_{3} \mathbf{L} \mathbf{4}$ (Figure $1 \mathrm{a}-\mathrm{d}$ ) used in this work are given in the Supporting Information SI-1. All other chemicals were purchased commercially and used without further purification. MIL-103(La) was synthesized according to the reported procedure. ${ }^{25,45}$ The synthesis of the isoreticular SUMOF-7s was derived from that of MIL-103, ${ }^{25}$ by adding DMF as a solvent to replace sodium hydroxide.

Preparation of SUMOF-7I ( $\mathbf{L n}=\mathrm{La}$ and Ce). $\mathrm{Ln}\left(\mathrm{NO}_{3}\right)_{3} \cdot x \mathrm{H}_{2} \mathrm{O}$ or $\mathrm{LnCl}_{3} \cdot x \mathrm{H}_{2} \mathrm{O}(0.100 \mathrm{mmol})$ and $\mathrm{H}_{3} \mathbf{L} \mathbf{1}(0.100 \mathrm{mmol})$ were dissolved in a mixture of DMF $(5 \mathrm{~mL})$, cyclohexanol $(2.5 \mathrm{~mL}), \mathrm{H}_{2} \mathrm{O}(1.25 \mathrm{~mL})$, and $\mathrm{HCl}(0.1 \mathrm{M}, 1.25 \mathrm{~mL})$. The solution was sealed in a $20 \mathrm{~mL}$ glass vial and heated at $85^{\circ} \mathrm{C}$ for $16 \mathrm{~h}$. The colorless needle-like SUMOF-7I crystals were filtered and washed with DMF and ethanol and dried at room temperature.

Preparation of SUMOF-7II ( $\mathrm{Ln}=\mathrm{La}, \mathrm{Ce}, \mathrm{Pr}, \mathrm{Nd}, \mathrm{Sm}, \mathrm{Eu}$, and Gd). $\mathrm{Ln}\left(\mathrm{NO}_{3}\right)_{3} \cdot x \mathrm{H}_{2} \mathrm{O}$ or $\mathrm{LnCl}_{3} \cdot x \mathrm{H}_{2} \mathrm{O}(0.011 \mathrm{mmol})$ and $\mathrm{H}_{3} \mathrm{~L} 2(0.011$ $\mathrm{mmol})$ were dissolved in a mixture of DMF $(0.1 \mathrm{~mL})$, cyclohexanol $(0.5 \mathrm{~mL}), \mathrm{H}_{2} \mathrm{O}(0.1 \mathrm{~mL})$, and $\mathrm{HCl}(0.1 \mathrm{M}, 0.1 \mathrm{~mL})$. The solution was sealed in a $2 \mathrm{~mL}$ glass vial and heated at $85{ }^{\circ} \mathrm{C}$ for $16 \mathrm{~h}$. The white crystalline powder was filtered, washed with DMF and ethanol, and dried at room temperature.

Preparation of SUMOF-7III ( $\mathrm{Ln}=\mathrm{La}, \mathrm{Ce}, \mathrm{Pr}, \mathrm{Nd}$, and $\mathrm{Eu}$ ). $\mathrm{Ln}\left(\mathrm{NO}_{3}\right)_{3} \cdot x \mathrm{H}_{2} \mathrm{O}$ or $\mathrm{LnCl}_{3} \cdot x \mathrm{H}_{2} \mathrm{O}(0.025 \mathrm{mmol})$ and $\mathrm{H}_{3} \mathbf{L} 3(0.025$ $\mathrm{mmol})$ were dissolved in a mixture of DMF $(1.25 \mathrm{~mL})$, cyclohexanol $(0.7 \mathrm{~mL}), \mathrm{H}_{2} \mathrm{O}(0.25 \mathrm{~mL})$, and $\mathrm{HCl}(0.1 \mathrm{M}, 0.25 \mathrm{~mL})$. The solution was sealed in a $20 \mathrm{~mL}$ glass vial and heated at $85{ }^{\circ} \mathrm{C}$ for $24 \mathrm{~h}$. The white crystalline powder was filtered, washed with DMF and ethanol, and dried at room temperature.

Preparation of SUMOF-7IV ( $\mathrm{Ln}=\mathrm{La}$ and Eu). $\mathrm{Ln}\left(\mathrm{NO}_{3}\right)_{3} \cdot x \mathrm{H}_{2} \mathrm{O}$ or $\mathrm{LnCl}_{3} \cdot x \mathrm{H}_{2} \mathrm{O}(0.072 \mathrm{mmol})$ and $\mathrm{H}_{3} \mathbf{L} 4(0.034 \mathrm{mmol})$ were dissolved in a mixture of DMF $(5 \mathrm{~mL})$, cyclohexanol $(2.5 \mathrm{~mL}), \mathrm{H}_{2} \mathrm{O}(0.3 \mathrm{~mL})$, and $\mathrm{HCl}(0.1 \mathrm{M}, 0.48 \mathrm{~mL})$. The solution was sealed in a $20 \mathrm{~mL}$ glass vial and heated at $85{ }^{\circ} \mathrm{C}$ for $24 \mathrm{~h}$. SUMOF-7IV was not stable in air, and thus the crystalline powder was kept in the mother liquid.

Loading of 2-aminoanthracene into SUMOF-7III $\left(\mathrm{La}_{0.90} \mathrm{Eu}_{0.10}\right)$. A saturated solution of 2 -aminoanthracene (2-AA) was prepared by dissolving 2-AA $(19 \mathrm{mg})$ in ethanol $(10 \mathrm{~mL})$. As-synthesized SUMOF$7 \mathrm{III}\left(\mathrm{La}_{0.90} \mathrm{Eu}_{0.10}\right)(5 \mathrm{mg})$ was immersed in the saturated 2-AA solution
$(2 \mathrm{~mL})$ for $12 \mathrm{~h}$ to afford yellow brown solid, which was filtered and washed carefully with ethanol. The final product is denoted as SUMOF-7III $\left(\mathrm{La}_{0.90} \mathrm{Eu}_{0.10}\right)$-2AA.

Powder X-ray Diffraction (PXRD) and Structure Refinement. PXRD patterns were collected on a PANanalytical X'Pert PRO diffractometer in Bragg-Brentano geometry equipped with a Pixel detector using $\mathrm{Cu} \mathrm{K} \alpha_{1}(\lambda=1.5406 \AA)$ radiation. SUMOF-7I, -7II, and $-7 \mathrm{III}$ were ground and dispersed on zero-background Si plates, while SUMOF-7IV was mixed with DMF prior to the data collection to avoid the decomposition of the structure. High quality PXRD patterns for Rietveld refinements were collected on the beamline I11 at Diamond Light Source, U.K. $(\lambda=0.8271 \AA$ ), for SUMOF-7II(La) and on a PANalytical X'Pert PRO MPD diffractometer in transmission geometry using $\mathrm{Cu} \mathrm{K} \alpha$ radiation for $\operatorname{SUMOF}-7 \mathrm{III}(\mathrm{Eu})$. Samples were sealed in $0.5 \mathrm{~mm}$ borosilicate capillaries. The Rietveld refinement of SUMOF-7II(La) and SUMOF-7III(Eu) and the Pawley profile fitting of SUMOF-7IV(La) were performed using Topas Academic V4.1.

Single Crystal X-ray Diffraction (SXRD) and Structural Analysis. Single crystal X-ray diffraction data of SUMOF-7I(La) and SUMOF-7I(Ce) and in situ single crystal X-ray diffraction data of SUMOF-7I $(\mathrm{La})$ were collected at room temperature on an Oxford Diffraction Xcalibur 3 diffractometer equipped with a CCD camera using Mo $\mathrm{K} \alpha$ radiation $(\lambda=0.71073 \AA)$. The crystal for the in situ measurement was heated under $\mathrm{N}_{2}$ flow from 100 to $500 \mathrm{~K}$ and then cooled down to room temperature with a heating/cooling rate of $10 \mathrm{~K}$. $\mathrm{min}^{-1}$ using Oxford Cryostream 600. The temperature was equilibrated for $1 \mathrm{~h}$ prior to each measurement. Single crystal X-ray diffraction data were first recorded at room temperature and then at $100 \mathrm{~K}, 323 \mathrm{~K}, 373 \mathrm{~K}, 423 \mathrm{~K}, 473 \mathrm{~K}, 500 \mathrm{~K}$, and finally at room temperature. Data reduction was performed using the CrysAlisPro program, and multiscan absorption correction was applied. The structures were solved by direct methods.

Transmission Electron Microscopy. 3D rotation electron diffraction (RED) data of MIL-103(La), SUMOF-7I(La), -7II(La), and $-7 \mathrm{III}(\mathrm{La})$ were collected on a JEOL JEM-2100 microscope operated at $200 \mathrm{kV}$ using a single-tilt tomography sample holder. The data collection was controlled using the RED data collection software. $^{55,56}$ High resolution transmission electron microscopy (HRTEM) images of SUMOF-7I(La) were taken on a JEOL JEM$2100 \mathrm{~F}$ microscope operated at $200 \mathrm{kV}$. 3D reciprocal lattices were reconstructed using the RED data processing software, ${ }^{55}$ from which the unit cell parameters were determined.

Other Characterizations. Scanning electron microscopy (SEM) was carried out on JEOL JSM-7000F and JEOL JSM-7401F. Thermogravimetric analysis (TGA) was performed in air from 30 ${ }^{\circ} \mathrm{C}$ to 600 or $700{ }^{\circ} \mathrm{C}$ with a heating rate of $5{ }^{\circ} \mathrm{C} / \mathrm{min}$ using a high resolution thermogravimetric analyzer (PerkinElmer TGA 7). Fluorescence spectroscopy data was recorded on a Varian Cary Eclipse Fluorescence spectrophotometer. Nitrogen sorption isotherms were measured at $77 \mathrm{~K}$ on a Micromeritics ASAP 2020 system. The samples were degassed at $200{ }^{\circ} \mathrm{C}$ for $12 \mathrm{~h}$ prior to the measurements. CHN elemental analysis was performed on a Carlo Erba Flash 1112 elemental analyzer. Inductively coupled plasma-optical emission spectrometry (ICP-OES) was used for the measurement of the La/ Eu ratio with a Varian Vista MPX ICP-OES instrument. Medac Ltd. in the U.K. carried out the elemental analyses.

\section{RESULTS AND DISCUSSION}

Design and Synthesis of SUMOF-7 Series. Among the two reported LnMOFs built from inorganic chains and tritopic linkers, $\mathrm{Tb}(\mathrm{BTB})\left(\mathrm{H}_{2} \mathrm{O}\right) \cdot\left(\mathrm{C}_{6} \mathrm{H}_{12} \mathrm{O}\right)_{2}(\mathrm{MIL}-103, \mathrm{BTB}=1,3,5$ benzenetrisbenzoate $)^{25}$ and $\operatorname{Ln}(\mathrm{BTC})\left(\mathrm{H}_{2} \mathrm{O}\right)(\mathrm{BTC}=1,3,5$ benzenetricarboxylate), ${ }^{26}$ only the tritopic linker in MIL-103 is connected to three $\mathrm{Ln}-\mathrm{O}$ chains, which is necessary for isoreticular expansion. MIL-103(Tb) consists of pseudohexagonal nanochannels (ca. 10.0 $\AA$ in diameter). It shows permanent porosity and has provided a unique platform for diverse applications. ${ }^{57-60}$ Considering the lack of preference in 
directionality of the $\mathrm{Ln}-\mathrm{O}$ bonds, we propose that the pore shape in MIL-103 $(\mathrm{Tb})$ depends mainly on the geometry of the linker. In other words, the direction of the $\mathrm{Ln}-\mathrm{O}$ bond can be imposed by the geometry of the linker and thus the framework structure can be directed. On the basis of this consideration, we envisaged that Ln-carboxylate inorganic chains could connect other tritopic linkers of various sizes to form pseudohexagonal channels with various aperture sizes.

According to this idea, we synthesized four different tritopic linkers based on tricarboxylic acids $\left(\mathrm{H}_{3} \mathbf{L} \mathbf{1}-\mathrm{H}_{3} \mathbf{L} \mathbf{4}\right)$ (Figure 1ad, Supporting Information SI-1), among which two of them, $\mathrm{H}_{3} \mathbf{L} \mathbf{2}$ and $\mathrm{H}_{3} \mathbf{L} 4$, are reported herein for the first time. The synthesis of SUMOF-7 series (SUMOF-7I to -7IV) was carried out by using $\mathrm{Ln}^{3+}$ salts and the corresponding carboxylic acid $\left(\mathrm{H}_{3} \mathbf{L} \mathbf{1}-\mathrm{H}_{3} \mathbf{L} \mathbf{4}\right)$ under solvothermal conditions, with minor variations in the experimental procedure for each compound (see Experimental Section and Supporting Information SI-2). Sixteen SUMOF-7s were synthesized under these conditions: SUMOF-7I $\left(\mathrm{H}_{3} \mathbf{L} \mathbf{1}\right.$ and $\mathrm{Ln}=\mathrm{La}$ and Ce $)$, SUMOF-7II $\left(\mathrm{H}_{3} \mathbf{L} 2\right.$ and $\mathrm{Ln}=\mathrm{La}, \mathrm{Ce}, \mathrm{Pr}, \mathrm{Nd}, \mathrm{Sm}, \mathrm{Eu}$, and Gd), SUMOF-7III $\left(\mathrm{H}_{3} \mathrm{~L} 3\right.$ and $\mathrm{Ln}=\mathrm{La}, \mathrm{Ce}, \mathrm{Pr}, \mathrm{Nd}$, and $\mathrm{Eu})$, and SUMOF-7IV $\left(\mathrm{H}_{3} \mathrm{~L} 4\right.$ and $\mathrm{Ln}=\mathrm{La}$ and $\mathrm{Eu})$. For characterization purposes, structural models of SUMOF-7I to -7IV were built with the tritopic linkers in the space group $R 32$ based on the crystal structure of MIL-103(Tb). ${ }^{25}$ There are one symmetry-independent Ln atom and one symmetry-independent tritopic linker in the unit cell. The inorganic Ln-carboxylate chain is located at the $3_{1}$ axis, while the center of the tritopic linker is located near the $3_{2}$ axis. Each Ln atom connects to six carboxylate groups from six tritopic linkers, and each tritopic linker connects to three Lncarboxylate chains to form a 3D framework with $1 \mathrm{D}$ pseudohexagonal channels along the $c$-axis. The rigidity of the Ln-carboxylate inorganic chains keeps the $c$-axis of the SUMOF-7 series almost unchanged, while the expansion of the tritopic linkers generates the different sizes of the 1D pseudohexagonal channels. On the basis of the models, we

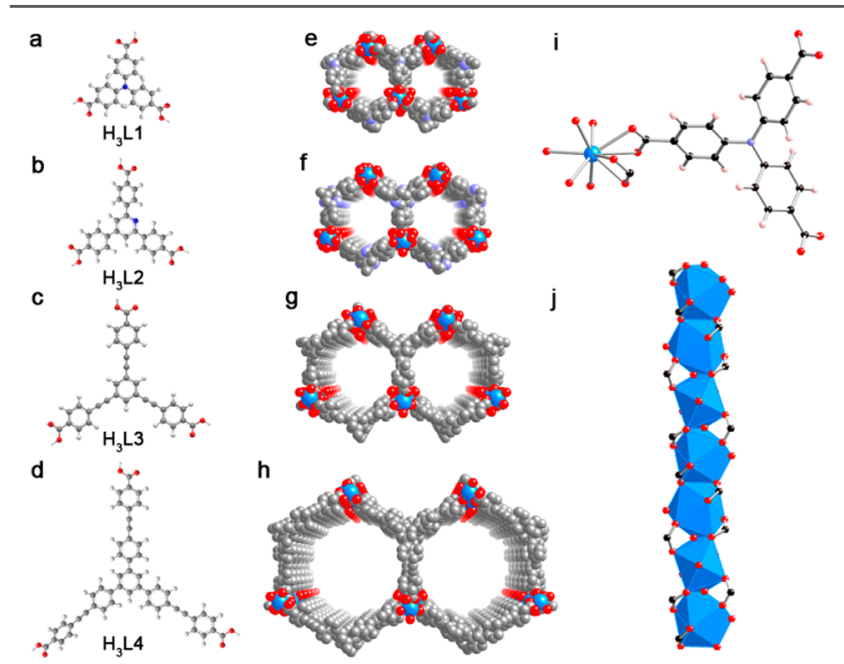

Figure 1. $(a-d)$ Structures of the tritopic organic linkers with different sizes used in the synthesis of SUMOF-7I to -7IV; $\mathrm{H}_{3} \mathbf{L} \mathbf{1}$ (a), $\mathrm{H}_{3} \mathbf{L} 2$ (b), $\mathrm{H}_{3} \mathrm{~L} 3$ (c), and $\mathrm{H}_{3} \mathrm{L4}(\mathrm{d})$. (e-h) Crystal structures of SUMOF-7I (e), SUMOF-7II (f), SUMOF-7III (g), and SUMOF-7IV (h). The diameters of the corresponding pore apertures are 8.4, 11.3, 16.3, and $23.9 \AA$, respectively (taking into account the van der Waals radii of the atoms). (i) The asymmetric unit of SUMOF-7I and (j) the 1D $\mathrm{La}-\mathrm{O}$ chain. calculated the unit cell parameters, PXRD patterns, pore apertures, and other related porosity information. The observed PXRD patterns matched very well with those calculated from the structural models, indicating the successful synthesis of the targeted MOF structures (Figure 2 and Supporting Information SI-4). SUMOF-7I, -7II, and -7III are highly crystalline, as shown by the sharp PXRD peaks (Figure 2 and Supporting Information SI-4). SEM images of the SUMOF-7s show the uniform triangular prism-like morphology, which further confirms the symmetry and phase purity of the synthesized MOFs (see Supporting Information SI-5). SUMOF-7IV showed poorer crystallinity compared to SUMOF-7I, -7II, and -7III and was only stable in the mother liquid (see Supporting Information SI-4). The intensity of the 110 reflection of SUMOF-7IV(La), i.e., the first peak in the PXRD pattern, is significantly lower compared to those of SUMOF-7I(La) to -7III(La) (Figure 2). This is because the PXRD data of SUMOF-7IV(La) was collected from a wet sample with a large amount of solvent present in the channels.

With the success of the reticular synthesis of the SUMOF-7 family, we further modified the composition by introducing two different lanthanide ions of various ratios in the SUMOF-7 framework. Different amounts of $\mathrm{Eu}^{3+}$ were successfully doped into SUMOF-7I $(\mathrm{La})(\mathrm{La} / \mathrm{Eu}=0.94: 0.06,0.90: 0.10 ; 0.87: 0.13$, and $0.73: 0.27)$ and SUMOF-7III $(\mathrm{La})(\mathrm{La} / \mathrm{Eu}=0.93: 0.07$; $0.89: 0.11$, and 0.49:0.51) without altering the crystallinity of the materials (Supporting Information SI-3 and SI-4). These results are very important because the luminescence properties of such solids strongly depend on the nature of the lanthanide ions.

Structural Analysis of the SUMOF-7 Series. Structural analysis of the SUMOF-7 series was carried out by combining single crystal X-ray diffraction, powder X-ray diffraction, and rotation electron diffraction techniques. Suitable crystals for single crystal X-ray diffraction could only be obtained for SUMOF-7I(La) and SUMOF-7I(Ce). Single crystal X-ray diffraction showed that the structure of SUMOF-7I(La) was in a good agreement with our structural model. It crystallizes in the space group $R 32$. The $\mathrm{La}^{3+}$ ions are nine-coordinated by eight carboxylate oxygen atoms from six carboxylate groups of L1 and one water molecule. The $\left[\mathrm{LaO}_{9}\right]$ polyhedrons are connected by edge-sharing to form inorganic La-carboxylate chain. The inorganic chains are connected by the tritopic L1 linkers to afford $1 \mathrm{D}$ pseudohexagonal channels along the $c$-axis

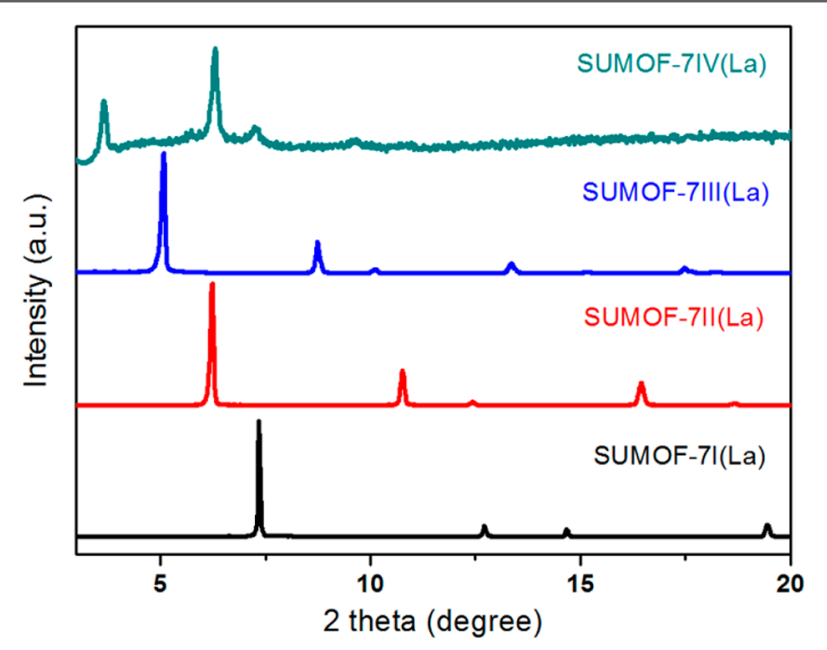

Figure 2. PXRD patterns of SUMOF-7I(La) to -7IV(La). 
with the aperture of ca. $8.4 \AA$ (by subtracting the van der Waals diameter of the oxygen or carbon atoms, Figure 1e).

Attempts to produce sufficiently large crystals of SUMOF7II, SUMOF-7III, and SUMOF-7IV for single crystal X-ray diffraction were unsuccessful. Instead, the newly developed rotation electron diffraction (RED) method, ${ }^{55,56}$ which enables the collection of almost complete three-dimensional electron diffraction data on micro- or nanosized single crystals, was employed to investigate the crystal structures of the SUMOF7s. RED data was collected on SUMOF-7I(La), SUMOF7II(La), and SUMOF-7III(La). Because SUMOF-7IV(La) collapses during solvent evacuation, no RED data could be collected. The three-dimensional reciprocal lattices of the SUMOF-7I(La) to SUMOF-7III(La) were reconstructed from the RED data (Figure 3), from which the unit cell parameters and space group were determined (see Table 1 and Supporting Information SI-8). SUMOF-7I(La) to -7III(La) crystallize in a trigonal system. The unit cell parameters $a$ and $b$ matched well with the isoreticular structural models. While the $c$ parameter of SUMOF-7I(La) is similar to that obtained by single crystal Xray diffraction, those of both SUMOF-7II(La) and -7III(La) were only about one-third of that for SUMOF-7I(La) (c/3). This is probably due to the removal of the guest water molecules under vacuum and/or by the electron beam radiation. In order to confirm this, RED data was collected on MIL-103(La), which also gave $1 / 3$ of the $c$ parameter determined by SXRD. Devic et al. also reported that the $c$ parameter of the fully dehydrated MIL-103(Eu) became 1/3 of the as-synthesized one. ${ }^{45}$ The structural rearrangement upon dehydration led to the change of the periodicity along $c$ to $1 / 3 c$, which seems to be dependent on the length or flexibility of the linkers. HRTEM image of SUMOF-7I(La) shows the presence of well-ordered straight channels along the $c$-axis (see Supporting Information Figure S8.2).

Finally, the unit cell parameters of the as-synthesized SUMOF-7II to -7IV were refined against the PXRD data,
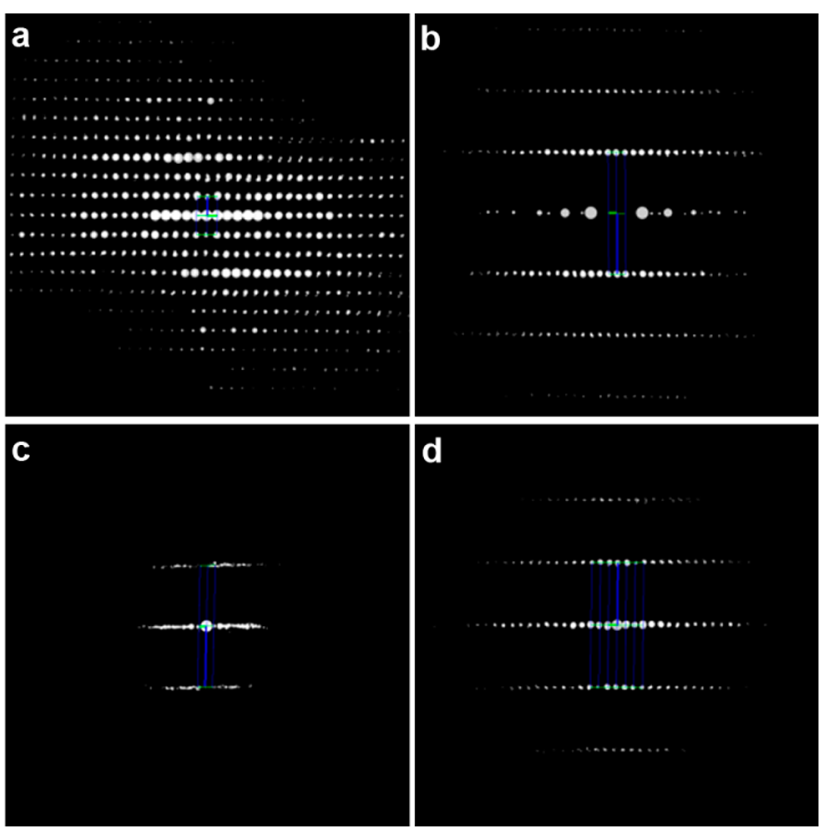

Figure 3. 3D reciprocal lattices obtained from reconstructed 3D RED data for (a) SUMOF-7I(La), (b) SUMOF-7II(La), (c) SUMOF$7 \mathrm{III}(\mathrm{La})$, and (d) MIL-103(La).
Table 1. Unit Cell Parameters of SUMOF-7I(La) to $-7 \mathrm{IV}(\mathrm{La})$ and MIL-103(La)

\begin{tabular}{lll}
\multicolumn{1}{c}{ material } & \multicolumn{1}{c}{$a(\AA)$} & \multicolumn{1}{c}{$c(\AA)$} \\
SUMOF-7I $^{a}$ & $24.1843(5)$ & $13.0217(5)$ \\
SUMOF-7I $^{b}$ & 23.80 & 12.72 \\
SUMOF-7II $^{b}$ & 27.82 & 3.85 \\
SUMOF-7III $^{b}$ & 31.40 & 3.92 \\
MIL-103 $^{45}$ & $28.736(3)$ & $12.47(1)$
\end{tabular}

${ }^{a}$ Determined from single crystal X-ray diffraction. ${ }^{b}$ Determined from rotation electron diffraction.

which confirmed the $c$ parameters. In addition, the structural models of SUMOF-7II(La) and SUMOF-7III(Eu) were refined against the high quality PXRD data by Rietveld refinement using Topas Academic version 4.1, with soft distance restraints for the $\mathrm{Ln}-\mathrm{O}$ bond distances $(2.5 \AA)$ and rigid body for the ligands. The guest species in the channel could not be located owing to their partial occupancies and low symmetry. Instead, several oxygen atoms were added at random positions inside the pores to compensate for the contributions of the guest species and refined subsequently. For SUMOF-7IV(La), the large fractional pore volume leads to broad Bragg peaks, relatively poor intensity, and low resolution of the diffraction data. Furthermore, the possibility of less ordering of the linkers within the pore walls cannot be ruled out. Although the quality of the PXRD pattern for SUMOF-7IV(La) does not allow us to perform a structural refinement, Pawley profile fitting of the PXRD data was applied to confirm the unit cell parameters. On the basis of the analyses described above, it can be confirmed that SUMOF-7II(La), SUMOF-7III(Eu), and SUMOF-7IV(La) have 1D pseudohexagonal channels with the pore aperture of 11.3, 16.3, and $23.9 \AA$, respectively.

Stability and Porosity. SUMOF-7I, -7II, and -7III show excellent thermal stability. Thermogravimetric analyses of assynthesized solids show that most coordinated water and guest molecules were released at 275,250 , and $150{ }^{\circ} \mathrm{C}$ for SUMOF7I, -7II, and -7III, respectively, to afford guest-free phases (see Supporting Information Figure S9.1). Subsequently, a long plateau is reached, and SUMOF-7I, -7II, and -7III are thermally stable up to 400,500 , and $370{ }^{\circ} \mathrm{C}$, respectively (see Supporting Information SI-9). For comparison, TGA was also performed on MIL-103(La) under the same condition. We found that MIL-103(La) was even more stable in air than the SUMOF-7 series (Supporting Information Figure S9.1). SUMOF-7II(La) and MIL-103(La), built from linkers with similar size but different chemical compositions, are both stable up to at least $500{ }^{\circ} \mathrm{C}$. This indicates that the high stability is mainly associated with the structure type. In situ PXRD shows that SUMOF-7II is stable to at least $475{ }^{\circ} \mathrm{C}$ in air, which is one of the most stable LnMOFs (Supporting Information SI-10).

In addition, SUMOF-7I, -7II, and -7III show exceptionally high chemical stability in water and DMF. All the activated SUMOF-7I, -7II, and -7III remained remarkably stable during treatment with hot solvents (DMF at $120{ }^{\circ} \mathrm{C}, \mathrm{H}_{2} \mathrm{O}$ at $100{ }^{\circ} \mathrm{C}$ for 1-30 days), as indicated by PXRD (see Figure 4 and Supporting Information SI-11). These MOFs are also stable in acidic or basic aqueous solutions with $\mathrm{pH}$ values ranging from 2 to 11 at room temperature (see Supporting Information SI-12). This exceptional resistance of the SUMOF-7I to -7III to hydrolysis is outstanding among the reported metal-organic frameworks. 


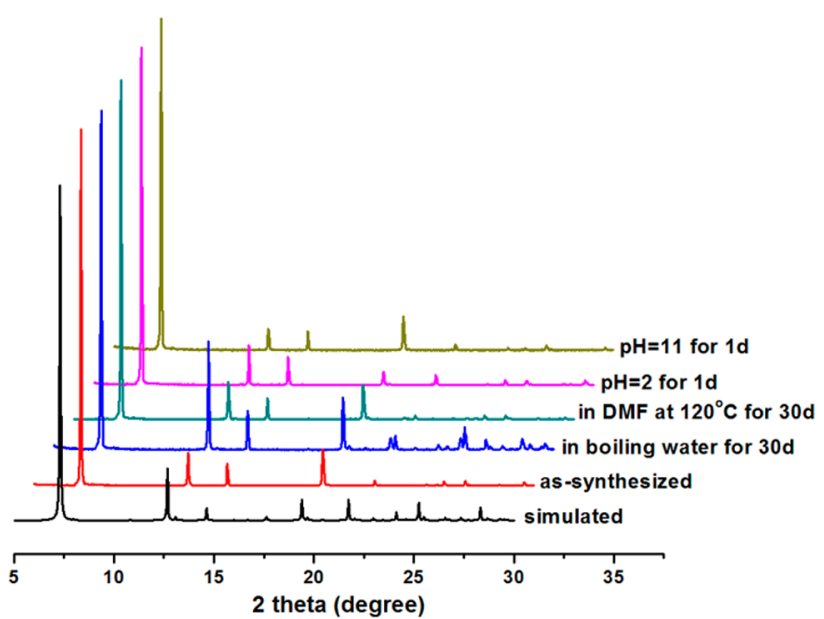

Figure 4. PXRD patterns of SUMOF-7I(La) under different treatments showing the high stability in solvent and acid/base conditions.

In order to evaluate the porosity of all compounds, their nitrogen sorption isotherms at $77 \mathrm{~K}$ were measured. SUMOF7I, -7II, and -7III exhibit Type I isotherms (Supporting Information Figure S13.1), with Langmuir surface areas of 1131,1319 , and $1814 \mathrm{~m}^{2} \mathrm{~g}^{-1}$ and BET surface areas of 780, 1002 , and $1489 \mathrm{~m}^{2} \mathrm{~g}^{-1}$, respectively. The pore volumes of SUMOF-7I, -7II, and -7III are 0.386, 0.453, and $0.653 \mathrm{~cm}^{3}$ and $\mathrm{g}^{-1}$, respectively (see Supporting Information Table S13.1). To the best of our knowledge, these compounds are among the most porous LnMOFs reported to date. $25,26,38,45$

Reversible Change of Coordination Environments. In situ SXRD study revealed that the symmetry and the framework structure of SUMOF-7I(La) were kept unchanged from 100 to $500 \mathrm{~K}$. It is interesting to investigate the behavior of the water molecule coordinated to the $\mathrm{La}^{3+}$ ion. With the increase of temperature, the bond length between the $\mathrm{La}^{3+}$ and the coordinated water molecule became longer, as shown in Figure 5. The water molecule was completely removed at 500 $\mathrm{K}$. At this temperature, $\mathrm{La}^{3+}$ ions are eight-coordinated to carboxylate oxygen atoms, resulting in an unsaturated metal site. This in situ SXRD study shows that the coordination environment of the metal centers in the MOF can be adjusted by change of the temperature. Finally, SXRD shows that the unsaturated metal sites were occupied again by water molecules, when the activated crystal was exposed to air for 1 day. This indicates that the unsaturated metal centers are accessible. This reversible dehydration phenomenon was also observed for MIL-103 by IR spectroscopy. ${ }^{45}$

Luminescence Properties. LnMOFs are excellent candidates for light-emitting devices because their color emission can be readily tuned both chemically (lanthanide ion types and concentration, ligand structure, coordination environment, guest species) and physically (excitation wavelength and temperature). ${ }^{30,61}$

The luminescence properties of SUMOF-7I to -7III were thoroughly investigated (see Supporting Information SI-14). Figure 6a shows the solid-state emission and excitation spectra of SUMOF-7III(La) and SUMOF-7III(Eu) at room temperature. When excited at $365 \mathrm{~nm}, \operatorname{SUMOF}-7 \mathrm{III}(\mathrm{La})$ shows a broad blue emission centered at $410 \mathrm{~nm}$ which can be ascribed to the $\pi^{*} \rightarrow \pi$ transition of the organic L3 linker, while SUMOF-7III(Eu) shows characteristic emission spectral
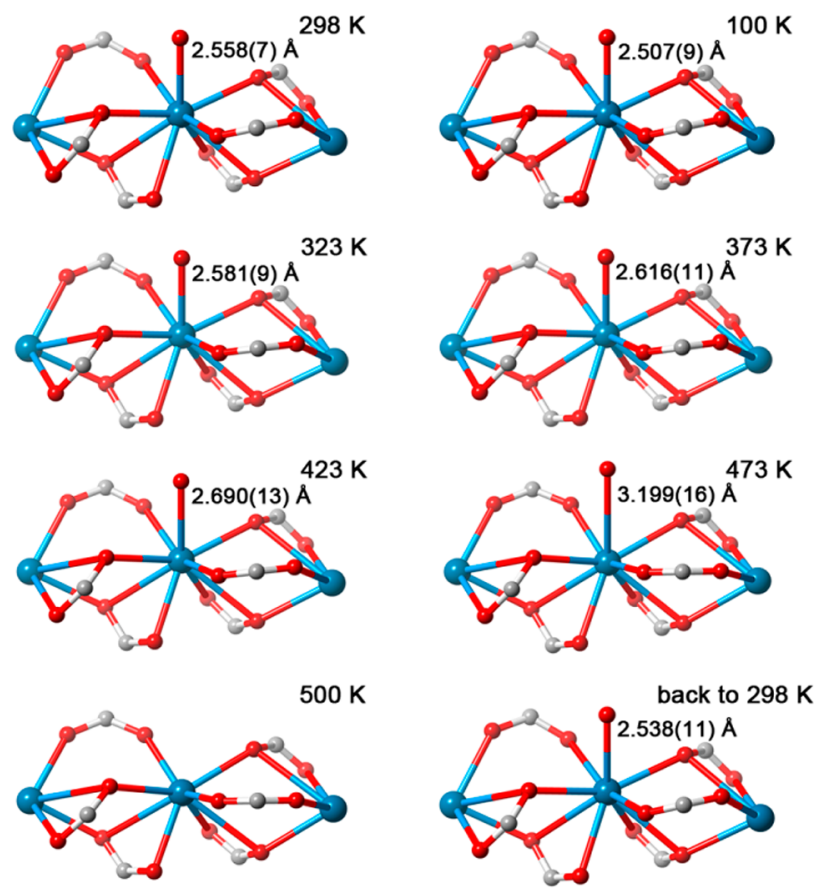

Figure 5. Change of the coordination environment around the $\mathrm{La}^{3+}$ ion in SUMOF-7I(La) with the temperature observed by in situ single crystal X-ray diffraction. La, O, and $\mathrm{C}$ atoms are shown in blue, red, and gray, respectively. The corresponding temperature and $\mathrm{La}-\mathrm{O}_{\mathrm{w}}$ distance are given.

features of $\mathrm{Eu}^{3+}$ ions at 593, 615, 653, and $698 \mathrm{~nm}$, which can be ascribed to the ${ }^{5} \mathrm{D}_{0} \rightarrow{ }^{7} \mathrm{~F}_{j}(j=1,2,3,4)$ transitions, respectively. It is worth noting that no emission from the $\mathbf{L} 3$ linker was observed in the SUMOF-7III(Eu). This indicates that the excitation energy harvested by the L3 linkers is efficiently transferred to the $\mathrm{Eu}^{3+}$ ions. Because SUMOF7III(La) and SUMOF-7III(Eu) are isostructural, it was anticipated that their emissions could be easily tuned by doping other lanthanide ions. Taking SUMOF-7III$\left(\mathrm{La}_{0.96} \mathrm{Eu}_{0.04}\right)$ and $-7 \mathrm{III}\left(\mathrm{La}_{0.90} \mathrm{Eu}_{0.10}\right)$ as the examples, besides the characteristic $f-f$ emission of $\mathrm{Eu}^{3+}$ ions, a broad emission band ascribed to the organic linkers can be detected, indicating the partial energy transfer from the $\mathbf{L} 3$ linker to the $\mathrm{Eu}^{3+}$ atom (Figure 6a). Meanwhile, the relative luminescence intensity between the lanthanide ions and ligands is strongly dependent on the excitation wavelength, thus allowing fine-tuning of the emission color (see Supporting Information Figure S14.4 and S14.5).

Importantly, the combination of large pore aperture and the stability in water makes SUMOF-7III a promising host matrix for accommodation of large functional organic molecules. Encapsulation of organic fluorescent molecules into the channels of the MOFs might generate interesting functions in applications as artificial photonic antennae, solid-state lasers, and light-emitting diodes. ${ }^{62-66}$ Such an approach to luminescence tuning or white light emission has not been previously realized in LnMOFs due to their usually narrow pores. We chose 2-aminoanthracene (2-AA) as the guest molecule due to its green color emission when excited using 300-450 nm and its molecular size that fits the pore of SUMOF-7III$\left(\mathrm{La}_{0.90} \mathrm{Eu}_{0.10}\right)$. The resulting host-guest complex was denoted as $\mathrm{SUMOF-7III}\left(\mathrm{La}_{0.90} \mathrm{Eu}_{0.10}\right)-2 \mathrm{AA}$. 

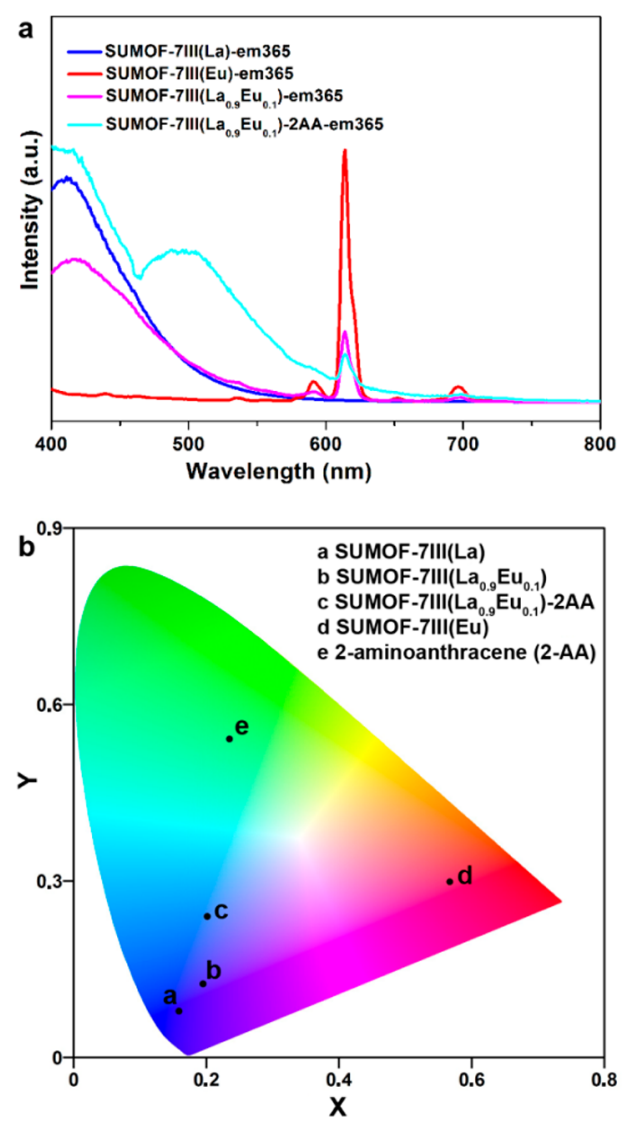

Figure 6. (a) Emission spectra of SUMOF-7III(La) (blue line), SUMOF-7III(Eu) (red line), SUMOF-7III $\left(\mathrm{La}_{0.9} \mathrm{Eu}_{0.1}\right)$ (pink line), and SUMOF-7III $\left(\mathrm{La}_{0.9} \mathrm{Eu}_{0.1}\right)-2 \mathrm{AA}$ (light blue line) when excited at $365 \mathrm{~nm}$ at room temperature and (b) CIE chromaticity coordinates of SUMOF-7III(La), SUMOF-7III $\left(\mathrm{La}_{0.9} \mathrm{Eu}_{0.1}\right)$, SUMOF-7III $\left(\mathrm{La}_{0.9} \mathrm{Eu}_{0.1}\right)$ 2AA, SUMOF-7III(Eu), and 2-aminoanthracene (2-AA).

As expected, this host-guest complex is able to create a nearly white emission, with CIE coordinates of $(0.20,0.24)$ (Figure 6b), which falls on the border of the white region of the 1931 CIE diagram (for "pure" white $x=0.33, y=0.33$ ). This indicates that a "pure" white emission could be possibly achieved by elaborate modulation of $\mathrm{Eu}^{3+}$ concentrations and the type and amount of guest molecules.

These interesting luminescence properties coupled with the outstanding structural robustness make the SUMOF-7s the promising candidates for applications as sensors, light-emitting devices, and multimodal imaging systems and also for biomedical use. ${ }^{30-32}$

\section{CONCLUSIONS}

We present the first series of isoreticular MOFs with expanding pore sizes built from inorganic chains and tritopic linkers, the SUMOF-7I to -7IV. SUMOF-7I, 7II, and -7III exhibit permanent porosity and exceptionally high thermal and chemical stability. The luminescence properties of the MOFs can be tuned by doping and/or inclusion of guest dye molecules in the channels. We strongly believe that the combination of tunable pore apertures, accessible metal sites, high thermal and chemical stability, and tunable luminescence properties makes the SUMOF-7 series a very promising platform for applications in optical sensing, heterogeneous catalysis, and photocatalysis.

\section{ASSOCIATED CONTENT}

\section{Supporting Information}

Detailed synthetic procedures for the linkers and the SUMOF-7 series, PXRD patterns, SEM images, structural analysis by SXRD and PXRD, TEM studies, TG analyses, thermal and chemical stability tests, $\mathrm{N}_{2}$ sorption isotherms, luminescence spectra, ${ }^{1} \mathrm{H}$ and ${ }^{13} \mathrm{C}$ NMR spectra, crystallographic information files (CIFs). The Supporting Information is available free of charge on the ACS Publications website at DOI: 10.1021/ acs.chemmater.5b01711.

\section{AUTHOR INFORMATION}

\section{Corresponding Authors}

*(X.Z.) E-mail: xzou@mmk.su.se.

*(B.M.-M.) E-mail: belen@organ.su.se.

\section{Present Addresses}

"(Q.Y.) Shandong Provincial Key Laboratory of Chemical Energy Storage and Novel Cell Technology, School of Chemistry and Chemical Engineering, Liaocheng University, Liaocheng, 252059, China.

${ }^{\perp}$ (A.B.G.) AstraZeneca Translational Science Center at Karolinska Institute, Stockholm, SE-171 65, Sweden.

\section{Author Contributions}

\#(Q.Y., A.B.G., and J.S.) These authors contributed to the work equally.

\section{Notes}

The authors declare no competing financial interest.

\section{ACKNOWLEDGMENTS}

This work is supported by the Swedish Research Council (VR) and the Swedish Governmental Agency for Innovation Systems (VINNOVA) through the Berzelii Center EXSELENT on Porous Materials and Röntgen-Ångström Cluster through VR. The structural characterization by TEM was supported by the Knut \& Alice Wallenberg Foundation through a grant for purchasing the TEM and the project grant 3DEM-NATUR. We acknowledge Diamond Light Source, U.K. (beamline I11), for the synchrotron powder X-ray diffraction beam time. B.M.-M. was supported by VINNOVA through a VINNMER grant. J.S. thanks the Wenner-Gren Foundations for a postdoctoral fellowship. Y.F.Y. and H.C. thank the China Scholarship Council (CSC)

\section{REFERENCES}

(1) Lu, W.; Wei, Z.; Gu, Z.-Y.; Liu, T.-F.; Park, J.; Park, J.; Tian, J.; Zhang, M.; Zhang, Q.; Gentle, T., III; Bosch, M.; Zhou, H.-C. Tuning the Structure and Function of Metal-Organic Frameworks via Linker Design. Chem. Soc. Rev. 2014, 43, 5561.

(2) Furukawa, H.; Cordova, K. E.; O’Keeffe, M.; Yaghi, O. M. The Chemistry and Applications of Metal-Organic Frameworks. Science 2013, 341, 1230444.

(3) Zhao, D.; Timmons, D. J.; Yuan, D.; Zhou, H.-C. Tuning the Topology and Functionality of Metal-Organic Frameworks by Ligand Design. Acc. Chem. Res. 2011, 44, 123.

(4) Zhao, X.; Bu, X.; Wu, T.; Zheng, S.-T.; Wang, L.; Feng, P. Selective Anion Exchange with Nanogated Isoreticular Positive MetalOrganic Frameworks. Nat. Commun. 2013, 4, 2344.

(5) Dau, V. P.; Kim, M.; Garibay, S. J.; Münch, H. L. F.; Moore, E. C.; Cohen, S. M. Single-Atom Ligand Changes Affect Breathing in an Extended Metal-Organic Framework. Inorg. Chem. 2012, 51, 5671.

(6) Zhang, Y.-B.; Zhou, H.-L.; Lin, R.-B.; Zhang, C.; Lin, J.-B.; Zhang, J.-P.; Chen, X.-M. Geometry Analysis and Systematic Synthesis of 
Highly Porous Isoreticular Frameworks with a Unique Topology. Nat. Commun. 2012, 3, 642.

(7) Ma, L.; Falkowski, J. M.; Abney, C.; Lin, W. A Series of Isoreticular Chiral Metal-Organic Frameworks as a Tunable Platform for Asymmetric Catalysis. Nat. Chem. 2010, 2, 838.

(8) Surblé, S.; Serre, C.; Mellot-Draznieks, C.; Millange, F.; Férey, G. A new Isoreticular Class of Metal-Organic Frameworks with the MIL88 Topology. Chem. Commun. 2006, 284.

(9) Eddaoudi, M.; Kim, J.; Rosi, N.; Vodak, D.; Wachter, J.; O’Keeffe, M.; Yaghi, O. M. Systematic Design of Pore Size and Functionality in Isoreticular MOFs and Their Application in Methane Storage. Science 2002, 295, 469.

(10) Serre, C.; Mellot-Draznieks, C.; Surblé, S.; Audebrand, N.; Filinchuk, Y.; Feréy, G. Role of Solvent-Host Interactions That Lead to Very Large Swelling of Hybrid Frameworks. Science 2007, 315, 1828.

(11) Férey, G.; Mellot-Draznieks, C.; Serre, C.; Millange, F.; Dutour, J.; Surblé, S.; Margiolaki, I. A Chromium Terephthalate-Based Solid with Unusually Large Pore Volumes and Surface Area. Science 2005, 309, 2040.

(12) Sonnauer, A.; Hoffmann, F.; Fröba, M.; Kienle, L.; Duppel, V.; Thommes, M.; Serre, C.; Férey, G.; Stock, N. Giant Pores in a Chromium 2,6-Naphthalenedicarboxylate Open-Framework Structure with MIL-101 Topology. Angew. Chem., Int. Ed. 2009, 48, 3791.

(13) Cavka, J. H.; Jakobsen, S.; Olsbye, U.; Guillou, N.; Lamberti, C.; Bordiga, S.; Lillerud, K. P. A New Zirconium Inorganic Building Brick Forming Metal Organic Frameworks with Exceptional Stability. J. Am. Chem. Soc. 2008, 130, 13850.

(14) Chui, S. S.-Y.; Lo, S. M.-F.; Charmant, J. P. H.; Orpen, A. G.; Williams, L. D. A Chemically Functionalizable Nanoporous Material. Science 1999, 283, 1148.

(15) Ma, S.; Sun, D.; Ambrogio, M.; Fillinger, J. A.; Parkin, S.; Zhou, H.-C. Framework-Catenation Isomerism in Metal-Organic Frameworks and Its Impact on Hydrogen Uptake. J. Am. Chem. Soc. 2007, $129,1858$.

(16) Furukawa, H.; Go, Y. B.; Ko, N.; Park, Y. K.; Uribe-Romo, F. J.; Kim, J.; O’Keeffe, M.; Yaghi, O. M. Isoreticular Expansion of MetalOrganic Frameworks with Triangular and Square Building Units and the Lowest Calculated Density for Porous Crystals. Inorg. Chem. 2011, 50, 9147.

(17) Yao, Q. X.; Su, J.; Zou, X. SUMOF-5: a Mesoporous MetalOrganic Framework with the tbo Topology Built from the Dicopper Paddle-Wheel Cluster and a New Tritopic Linker. Z. Kristallogr. Cryst. Mater. 2013, 228, 323.

(18) Feng, D.; Liu, T.-F.; Su, J.; Bosch, M.; Wei, Z.; Wan, W.; Chen, Y.-P.; Wang, X.; Wang, K.; Lian, X.; Gu, Z.-Y.; Yuan, Y.; Zou, X.; Zhou, H.-C.; Park, J. Stable Metal-Organic Frameworks Containing Single-Molecule Traps for Enzyme Encapsulation. Nat. Commun. 2015, 6, 5979.

(19) Liu, T.-F.; Feng, D.; Chen, Y.-P.; Zou, L.; Bosch, M.; Yuan, S.; Wei, Z.; Fordham, S.; Wang, K.; Zhou, H.-C. Topology-Guided Design and Syntheses of Highly Stable Mesoporous Porphyrinic Zirconium Metal-Organic Frameworks with High Surface Area. J. Am. Chem. Soc. 2015, 137, 413.

(20) Wang, T. C.; Bury, W.; Gómez-Gualdrón, D. A.; Vermeulen, N. A.; Mondloch, J. E.; Deria, P.; Zhang, K.; Moghadam, P. Z.; Sarjeant, A. A.; Snurr, R. Q.; Stoddart, J. F.; Hupp, J. T.; Farha, O. K. Ultrahigh Surface Area Zirconium MOFs and Insights into the Applicability of the BET Theory. J. Am. Chem. Soc. 2015, 137, 3585.

(21) Rosi, N. L.; Kim, J.; Eddaoudi, M.; Chen, B.; O'Keeffe, M.; Yaghi, O. M. Rod Packings and Metal-Organic Frameworks Constructed from Rod-Shaped Secondary Building Units. J. Am. Chem. Soc. 2005, 127, 1504.

(22) Deng, H.; Grunder, S.; Cordova, K. E.; Valente, C.; Furukawa, H.; Hmadeh, M.; Gándara, F.; Whalley, A. C.; Liu, Z.; Asahina, S.; Kazumori, H.; O’Keeffe, M.; Terasaki, O.; Stoddart, J. F.; Yaghi, O. M. Large-Pore Apertures in a Series of Metal-Organic Frameworks. Science 2012, 336, 1018.
(23) Wharmby, M. T.; Mowat, J. P. S.; Thompson, S. P.; Wright, P. A. Extending the Pore Size of Crystalline Metal Phosphonates toward the Mesoporous Regime by Isoreticular Synthesis. J. Am. Chem. Soc. 2011, 133, 1266.

(24) Guillerm, V.; Ragon, F.; Dan-Hardi, M.; Devic, T.; Vishnuvarthan, M.; Campo, B.; Vimont, A.; Clet, G.; Yang, Q.; Maurin, G.; Férey, G.; Vittadini, A.; Gross, S.; Serre, C. A Series of Isoreticular, Highly Stable, Porous Zirconium Oxide Based MetalOrganic Frameworks. Angew. Chem., Int. Ed. 2012, 51, 9267.

(25) Devic, T.; Serre, C.; Audebrand, N.; Marrot, J.; Férey, G. MIL103, A 3-D Lanthanide-Based Metal Organic Framework with Large One-Dimensional Tunnels and A High Surface Area. J. Am. Chem. Soc. 2005, 127, 12788.

(26) Gustafsson, M.; Bartoszewicz, A.; Martín-Matute, B.; Sun, J.; Grins, J.; Zhao, T.; Li, Z.; Zhu, G.; Zou, X. A Family of Highly Stable Lanthanide Metal-Organic Frameworks: Structural Evolution and Catalytic Activity. Chem. Mater. 2010, 22, 3316.

(27) Tang, Q.; Liu, S.; Liu, Y.; He, D.; Miao, J.; Wang, X.; Ji, Y.; Zheng, Z. Color Tuning and White Light Emission via in Situ Doping of Luminescent Lanthanide Metal-Organic Frameworks. Inorg. Chem. 2014, 53, 289.

(28) Cui, Y.; Xu, H.; Yue, Y.; Guo, Z.; Yu, J.; Chen, Z.; Gao, J.; Yang, Y.; Qian, G.; Chen, B. A Luminescent Mixed-Lanthanide MetalOrganic Framework Thermometer. J. Am. Chem. Soc. 2012, 134, 3979.

(29) Cui, Y.; Yue, Y.; Qian, G.; Chen, B. Luminescent Functional Metal-Organic Frameworks. Chem. Rev. 2012, 112, 1126.

(30) Rocha, J.; Carlos, L. D.; Paz, F. A. A.; Ananias, D. Luminescent Multifunctional Lanthanides-Based Metal-Organic Frameworks. Chem. Soc. Rev. 2011, 40, 926.

(31) Allendorf, M. D.; Bauer, C. A.; Bhakta, R. K.; Houk, R. J. T. Luminescent Metal-Organic Frameworks. Chem. Soc. Rev. 2009, 38, 1330.

(32) Chen, B.; Yang, Y.; Zapata, F.; Lin, G.; Qian, G.; Lobkovsky, E. B. Luminescent Open Metal Sites within a Metal-Organic Framework for Sensing Small Molecules. Adv. Mater. 2007, 19, 1693.

(33) Taylor, K. M. L.; Jin, A.; Lin, W. Surfactant-Assisted Synthesis of Nanoscale Gadolinium Metal-Organic Frameworks for Potential Multimodal Imaging. Angew. Chem., Int. Ed. 2008, 47, 7722.

(34) Rieter, W. J.; Taylor, K. M. L.; An, H.; Lin, W.; Lin, W. Nanoscale Metal-Organic Frameworks as Potential Multimodal Contrast Enhancing Agents. J. Am. Chem. Soc. 2006, 128, 9024.

(35) Liu, Y.; Mo, K.; Cui, Y. Porous and Robust Lanthanide MetalOrganoboron Frameworks as Water Tolerant Lewis Acid Catalysts. Inorg. Chem. 2013, 52, 10286.

(36) Hu, Z.; Deibert, B. J.; Li, J. Luminescent Metal-Organic Frameworks for Chemical Sensing and Explosive Detection. Chem. Soc. Rev. 2014, 43, 5815.

(37) Sava Gallis, D. F.; Rohwer, L. E. S.; Rodriguez, M. A.; Nenoff, T. M. Efficient Photoluminescence via Metal-Ligand Alteration in a New MOFs Family. Chem. Mater. 2014, 26, 2943.

(38) Guillerm, V.; Weseliński, Ł. J.; Belmabkhout, Y.; Cairns, A. J.; D’Elia, V.; Wojtas, Ł.; Adil, K.; Eddaoudi, M. Discovery and Introduction of a $(3,18)$-Connected Net as an Ideal Blueprint for the Design of Metal-Organic Frameworks. Nat. Chem. 2014, 6, 673.

(39) He, Y.-P.; Tan, Y.-X.; Zhang, J. Gas Sorption, Second-Order Nonlinear Optics, and Luminescence Properties of a Series of Lanthanide-Organic Frameworks Based on Nanosized Tris((4carboxyl)phenylduryl)amine Ligand. Inorg. Chem. 2013, 52, 12758.

(40) He, Y.; Furukawa, H.; Wu, C.; O'Keeffe, M.; Chen, B. A Mesoporous Lanthanide-Organic Framework Constructed from a Dendritic Hexacarboxylate with Cages of $2.4 \mathrm{~nm}$. CrystEngComm 2013, 15, 9328

(41) Kajiwara, T.; Higuchi, M.; Yuasa, A.; Higashimura, H.; Kitagawa, S. One-Dimensional Alignment of Strong Lewis Acid Sites in a Porous Coordination Polymer. Chem. Commun. 2013, 49, 10459.

(42) Duan, J.; Higuchi, M.; Foo, M. L.; Horike, S.; Rao, K. P.; Kitagawa, S. A Family of Rare Earth Porous Coordination Polymers with Different Flexibility for $\mathrm{CO}_{2} / \mathrm{C}_{2} \mathrm{H}_{4}$ and $\mathrm{CO}_{2} / \mathrm{C}_{2} \mathrm{H}_{6}$ Separation. Inorg. Chem. 2013, 52, 8244. 
(43) Tang, K.; Yun, R.; Lu, Z.; Du, L.; Zhang, M.; Wang, Q.; Liu, H. High $\mathrm{CO}_{2} / \mathrm{N}_{2}$ Selectivity and $\mathrm{H}_{2}$ Adsorption of a Novel Porous Yttrium Metal-Organic Framework Based on N,N,N-Tris(isophthalyl)-1,3,5-benzenetricarboxamide. Cryst. Growth Des. 2013, 13, 1382.

(44) He, Y.; Xiang, S.; Zhang, Z.; Xiong, S.; Fronczek, F. R.; Krishna, R.; O’Keeffe, M.; Chen, B. A Microporous Lanthanide-Tricarboxylate Framework with the Potential for Purification of Natural Gas. Chem. Commun. 2012, 48, 10856.

(45) Devic, T.; Wagner, V.; Guillou, N.; Vimont, A.; Haouas, M.; Pascolini, M.; Serre, C.; Marrot, J.; Daturi, M.; Taulelle, F.; Férey, G. Synthesis and Characterization of a Series of Porous Lanthanide Tricarboxylates. Microporous Mesoporous Mater. 2011, 140, 25.

(46) Jiang, H.-L.; Tsumori, N.; Xu, Q. A Series of $(6,6)$-Connected Porous Lanthanide-Organic Framework Enantiomers with High Thermostability and Exposed Metal Sites: Scalable Syntheses, Structures, and Sorption Properties. Inorg. Chem. 2010, 49, 10001.

(47) Lee, W. R.; Ryu, D. W.; Lee, J. W.; Yoon, J. H.; Koh, E. K.; Hong, C. S. Microporous Lanthanide-Organic Frameworks with Open Metal Sites: Unexpected Sorption Propensity and Multifunctional Properties. Inorg. Chem. 2010, 49, 4723.

(48) Chen, B.; Wang, L.; Xiao, Y.; Fronczek, F. R.; Xue, M.; Cui, Y.; Qian, G. A Luminescent Metal-Organic Framework with Lewis Basic Pyridyl Sites for the Sensing of Metal Ions. Angew. Chem., Int. Ed. 2009, 48, 500 .

(49) Qiu, Y.; Deng, H.; Yang, S.; Mou, J.; Daiguebonne, C.; Kerbellec, N.; Guillou, O.; Batten, S. R. Syntheses, Crystal Structures, and Gas Storage Studies in New Three-Dimensional 5-Aminoisophthalate Praseodymium Polymeric Complexes. Inorg. Chem. 2009, 48, 3976.

(50) Ma, S.; Yuan, D.; Wang, X.-S.; Zhou, H.-C. Microporous Lanthanide Metal-Organic Frameworks Containing Coordinatively Linked Interpenetration: Syntheses, Gas Adsorption Studies, Thermal Stability Analysis, and Photoluminescence Investigation. Inorg. Chem. 2009, 48, 2072.

(51) Park, Y. K.; Choi, S. B.; Kim, H.; Kim, K.; Won, B.-H.; Choi, K.; Choi, J.-S.; Ahn, W.-S.; Won, N.; Kim, S.; Jung, D. H.; Choi, S.-H.; Kim, G.-H.; Cha, S.-S.; Jhon, Y. H.; Yang, J. K.; Kim, J. Crystal Structure and Guest Uptake of a Mesoporous Metal-Organic Framework Containing Cages of 3.9 and $4.7 \mathrm{~nm}$ in Diameter. Angew. Chem., Int. Ed. 2007, 46, 8230.

(52) Guo, X.; Zhu, G.; Li, Z.; Sun, F.; Yang, Z.; Qiu, S. A Lanthanide Metal-Organic Framework with High Thermal Stability and Available Lewis-Acid Metal Sites. Chem. Commun. 2006, 3172.

(53) Jia, J.; Lin, X.; Blake, A. J.; Champness, N. R.; Hubberstey, P.; Shao, L.; Walker, G.; Wilson, C.; Schröder, M. Triggered Ligand Release Coupled to Framework Rearrangement: Generating Crystalline Porous Coordination Materials. Inorg. Chem. 2006, 45, 8838.

(54) Karraker, D. G. Coordination of Trivalent Lanthanide Ions. J. Chem. Educ. 1970, 47, 424.

(55) Wan, W.; Sun, J.; Su, J.; Hovmoller, S.; Zou, X. ThreeDimensional Rotation Electron Diffraction: Software RED for Automated Data Collection and Data Processing. J. Appl. Crystallogr. 2013, 46, 1863.

(56) Zhang, D.; Oleynikov, P.; Hovmöller, S.; Zou, X. Collecting 3D Electron Diffraction Data by the Rotation Method. Z. Kristallogr. 2010, 225, 94.

(57) Duan, J.; Higuchi, M.; Horike, S.; Foo, M. L.; Rao, K. P.; Inubushi, Y.; Fukushima, T.; Kitagawa, S. High $\mathrm{CO}_{2} / \mathrm{CH}_{4}$ and $\mathrm{C} 2$ Hydrocarbons $/ \mathrm{CH}_{4}$ Selectivity in a Chemically Robust Porous Coordination Polymer. Adv. Funct. Mater. 2013, 23, 3525.

(58) Uemura, T.; Uchida, N.; Asano, A.; Saeki, A.; Seki, S.; Tsujimoto, M.; Isoda, S.; Kitagawa, S. Highly Photoconducting $\pi-$ Stacked Polymer Accommodated in Coordination Nanochannels. J. Am. Chem. Soc. 2012, 134, 8360.

(59) Choi, J. R.; Tachikawa, T.; Fujitsuka, M.; Majima, T. EuropiumBased Metal-Organic Framework as a Photocatalyst for the OneElectron Oxidation of Organic Compounds. Langmuir 2010, 26, 10437.
(60) Vitorino, M. J.; Devic, T.; Tromp, M.; Férey, G.; Visseaux, M. Lanthanide Metal-Organic Frameworks as Ziegler-Natta Catalysts for the Selective Polymerization of Isoprene. Macromol. Chem. Phys. 2009, 210, 1923.

(61) Zhou, Y.; Yan, B.; Lei, F. Postsynthetic Lanthanide Functionalization of Nanosized Metal-Organic Frameworks for Highly Sensitive Ratiometric Luminescent Thermometry. Chem. Commun. 2014, 50, 15235.

(62) Dong, M.-J.; Zhao, M.; Ou, S.; Zou, C.; Wu, C.-D. A Luminescent Dye@MOF Platform: Emission Fingerprint Relationships of Volatile Organic Molecules. Angew. Chem., Int. Ed. 2014, 53, 1575.

(63) Calzaferri, G.; Huber, S.; Maas, H.; Minkowski, C. Host-Guest Antenna Materials. Angew. Chem., Int. Ed. 2003, 42, 3732.

(64) Pauchard, M.; Huber, S.; Méallet-Renault, R.; Maas, H.; Pansu, R; Calzaferri, G. Time- and Space-Resolved Luminescence of a Photonic Dye-Zeolite Antenna. Angew. Chem., Int. Ed. 2001, 40, 2839.

(65) Yang, P.; Wirnsberger, Gernot; Huang, H. C.; Cordero, S. R.; McGehee, M. D.; Scott, B.; Deng, T.; Whitesides, G. M.; Chmelka, B. F.; Buratto, S. K.; Stucky, G. D. Mirrorless Lasing from Mesostructured Waveguides Patterned by Soft Lithography. Science 2000, 287, 465 .

(66) Del Monte, F.; Mackenzie, J. D.; Levy, D. Rhodamine Fluorescent Dimers Adsorbed on the Porous Surface of Silica Gels. Langmuir 2000, 16, 7377. 